Case Report

\title{
Papillary Squamotransitional Cell Carcinoma of the Uterine Cervix: A Case Report and Review of the Literature
}

\author{
Shomaila Aamir M. Akbar, ${ }^{1}$ Mutahir A. Tunio, ${ }^{1}$ Sadeq Al-Dandan, ${ }^{2,3,4}$ \\ Kareema Mohammed Y. Salamah, ${ }^{5}$ and Mushabbab AlAsiri ${ }^{1}$ \\ ${ }^{1}$ Radiation Oncology, Comprehensive Cancer Center, King Fahad Medical City, Riyadh 59046, Saudi Arabia \\ ${ }^{2}$ Surgical Pathology, Department of Pathology and Laboratory Medicine Administration, King Fahad Medical City, \\ Riyadh 59046, Saudi Arabia \\ ${ }^{3}$ King Saud bin Abdulaziz University, Riyadh, Saudi Arabia \\ ${ }^{4}$ King Saud University, Riyadh, Saudi Arabia \\ ${ }^{5}$ Gynecology Oncology, Women's Hospital, King Fahad Medical City, Riyadh 59046, Saudi Arabia \\ Correspondence should be addressed to Mutahir A. Tunio; mkhairuddin@kfmc.med.sa
}

Received 18 June 2016; Accepted 14 August 2016

Academic Editor: Kyousuke Takeuchi

Copyright (C) 2016 Shomaila Aamir M. Akbar et al. This is an open access article distributed under the Creative Commons Attribution License, which permits unrestricted use, distribution, and reproduction in any medium, provided the original work is properly cited.

\begin{abstract}
Introduction. Papillary squamotransitional cell carcinoma (PSTCC) is an uncommon histopathological variant of squamous cell carcinoma (SCC) of the uterine cervix, which occurs in postmenopausal women. Presentation of Case. Herein, we describe a case of a 63-year-old woman who presented with 4-month history of postmenopausal vaginal bleeding. Vaginal examination revealed a fragile lesion of size $1 \times 1 \mathrm{~cm}$ invading left posterior vaginal fornice and parametrium. Biopsy showed the presence of papillae containing fibrovascular cores lined by multilayered atypical epithelial cells resembling squamous and transitional cell epithelium, confirming the diagnosis of PSTCC of the uterine cervix. After staging work-up she was staged according to the International Federation of Gynecology and Obstetrics (FIGO) staging system 2009 as FIGO IIB, and she was started on extended field concurrent chemoradiation. Discussion. PSTCC of the uterine cervix is an extremely rare and aggressive entity. PSTCC is often characterized by the presence of papillary structures with prominent fibrovascular cores. PSTCC of the uterine cervix should be differentiated from transitional cell carcinoma, squamous papilloma, papillary adenocarcinoma, and cervical intraepithelial neoplasia with papillary features. Conclusion. PSTCC of the uterine cervix is a diagnostic challenge; further studies regarding the mechanism underlying the development of PSCC are warranted.
\end{abstract}

\section{Introduction}

Papillary squamotransitional cell carcinoma (PSTCC) of the uterine cervix is an uncommon histopathological variant [1]. PSTCC have been reported also at other sites of the female genital tract (uterus, ovaries, and vagina) [2,3]. These tumors show a broad spectrum of morphology, as these can appear as either "papillary squamous cell carcinoma (PSCC)" or "papillary transitional cell carcinoma (PTCC)" or mixed (PSTCC) [4]. However, a large series have shown that PSTCC variant is more predominant $(50 \%)$ as compared to PSCC (28.1\%) and PTCC (21.9\%) [5].

As PSTCC are typically recognized due to its distinctive pattern of papillary growth pattern, these tumors should be segregated from transitional cell carcinoma, squamous papilloma, verrucous carcinoma, papillary serous adenocarcinoma, and cervical intraepithelial neoplasia especially grade III with papillary features [6, 7].

PSTCC of the uterine cervix is considered to be associated with an aggressive biologic behavior, as it mainly presents at a more advanced stage, and high propensity for locoregional recurrence and distant metastasis, in spite of the histopathological evidence suggesting a superficial or early invasive lesion [8].

Herein we present the clinicopathological presentation of PSTCC of the uterine cervix in a 63-year-old postmenopausal woman and relevant literature review. 


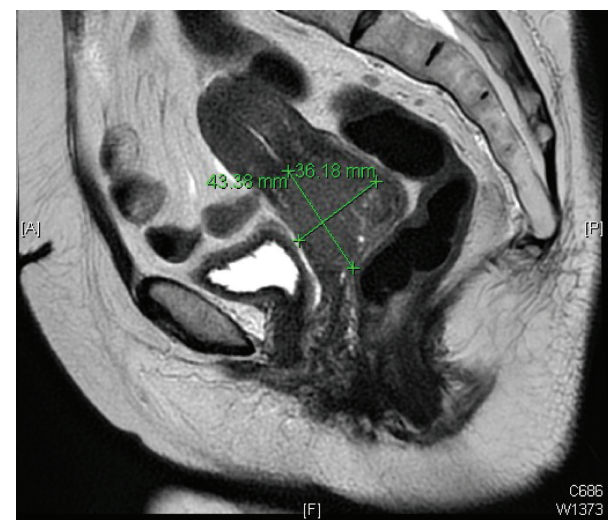

FIgURE 1: Sagittal view of pelvic MRI showing $4.3 \times 3.6 \mathrm{~cm}$ cervical mass extending to the lower uterine segment (LUS) and left vaginal fornix with evidence of parametrial invasion on the left side.

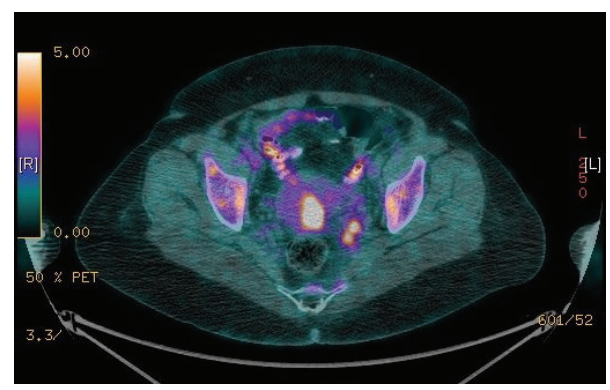

FIGURE 2: CT-PET imaging showing uptake in two left internal iliac lymph nodes and uptake in right external iliac small lymph node.

\section{Case Presentation}

A 63-year-old female presented in our clinic with 4-month history of postmenopausal bleeding and pelvic pain, which was increasing in intensity over two months; however, she denied any weight loss, fever, or altered bowel habits. Her previous medical history revealed hypertension and chronic left ventricular dysfunction since the last 10 years; for that she was taking antihypertensive drugs and warfarin $5 \mathrm{mg}$ daily. On physical assessment, she was pale with good performance status (Eastern Co-operative Oncology Group; ECOG-1). Per vaginal examination showed a fragile easily bleeding fungating lesion of size $1 \times 1 \mathrm{~cm}$ invading the left posterior vaginal fornice and left parametrium. Hematology showed low hemoglobin (8.1 grams/deciliter), while other laboratory tests including serum electrolytes, renal, and hepatic function tests were found within normal limits.

Magnetic resonance imaging (MRI) showed $4.3 \times 3.6 \mathrm{~cm}$ cervical mass extending to the lower uterine segment (LUS) and left vaginal fornix with evidence of parametrial invasion on the left side and bilateral pelvic lymphadenopathy. Two left internal iliac enlarged lymph nodes, the largest measuring about $1.1 \mathrm{~cm}$ at short axis, and right external iliac small lymph node measuring $0.7 \mathrm{~cm}$ at short axis (Figure 1) were present. Computed tomography- (CT-) positron emission tomography (PET) confirmed the MRI findings with no evidence of distant metastasis (Figure 2).

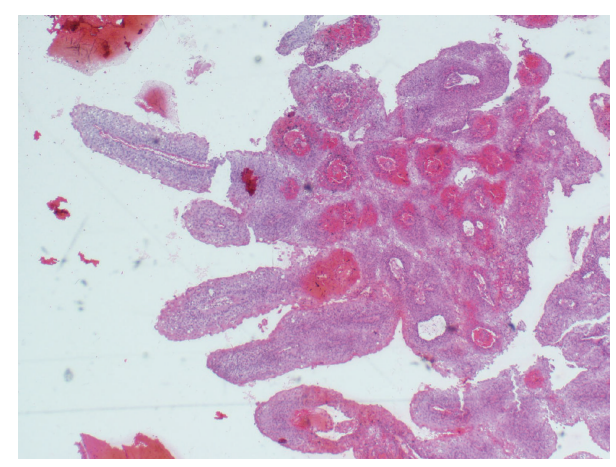

FIGURE 3: Cervical biopsy superficial fragment of papillary structures each containing a delicate fibrovascular core (H\&E stain, 40x magnifications).

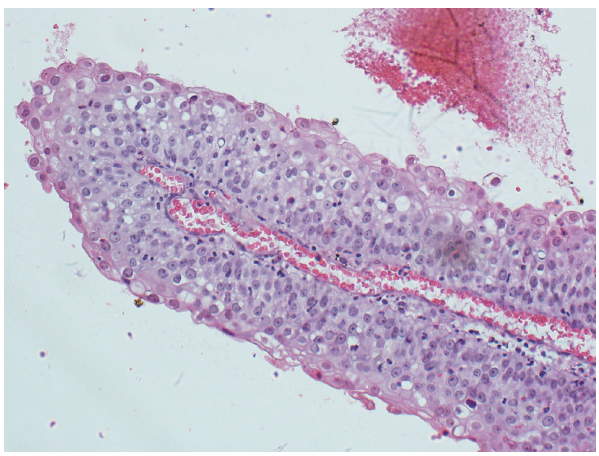

FIGURE 4: Papillary formation with squamotransitional cells having polygonal shape, distinct cell borders, abundant eosinophilic cytoplasm, pleomorphic nuclei, prominent nucleoli, and occasional mitotic figures (H\&E stain, 200x magnifications).

A cervical biopsy was taken. Hematoxylin and eosin (H\&E) staining showed a superficial fragment of papillary structures, each containing a delicate fibrovascular core, lined by multilayered atypical epithelial cells resembling squamous and transitional type epithelium, favoring the diagnosis of PSTCC (Figures 3 and 4).

After staging work-up she was staged according to the International Federation of Gynecology and Obstetrics (FIGO) staging system 2009 as FIGO IIB. After the multidisciplinary board meeting, patient was started on extended field concurrent chemoradiation. Radiotherapy dose was prescribed to para-aortic and pelvic fields at 45 Gy in 25 fractions at $1.8 \mathrm{~Gy} /$ fraction, followed by a parametrial boost ( $9 \mathrm{~Gy}$ at $1.8 \mathrm{~Gy} / 5$ fractions to complete $54 \mathrm{~Gy}$ ) with concurrent weekly cisplatin, followed by high dose rate (HDR) brachytherapy of $21 \mathrm{~Gy}$ in 3 sessions.

\section{Discussion}

PSTCC of the uterine cervix is an extremely rare entity, and the presence of bland-looking basaloid cells or high grade squamous intraepithelial lesions (HSILs), together with scantiness of malignant cells, may lead to underdiagnosis of these histopathological variants $[1,9,10]$. Thus the 
identification of the subtle cytological characteristics with clinical correlation is mandatory to conclude diagnostic and staging dilemma. Further, on histopathological specimens, the stromal invasion is very difficult to see unless deep biopsies are taken, which can be a difficult process due to complex papillary architecture of PSTCC. However, in most of reported cases, stromal invasion varies between $55 \%$ and $65 \%[1,5,6]$.

The clinical manifestation of our patients was similar to other cases reports, that is, age above 60 years with postmenopausal bleeding [5-8]. However, our patient presented with severe vaginal bleeding, severe anemia, and presence of pelvic lymphadenopathy in spite of small cervical lesion.

Though follow-up period was short in our patient, PSTCC is known to be associated with delayed locoregional recurrences and metastasis $[5,11]$. Tumor-suppressor protein p16 to predict the presence of human papillomavirus (HPV) was not investigated in our patients; however, previously published reports have supported the association of HPV and progression of PSTCC through an in situ phase $[1,5,12]$.

In conclusion, PSTCC of uterine cervix is an uncommon histopathological variant, and the true prevalence remained undefined due to presence of bland-looking basaloid cells or HSILs, together with scantiness of malignant cells. PSTCC of uterine cervix is commonly seen in women aged above 60 years, known to be associated with HPV and present with delayed locoregional recurrences and distant metastasis. Due to rarity of PSTCC, treatment is similar to squamous cell carcinoma or adenocarcinoma of cervix.

\section{Consent}

Written informed consent was taken from patient for the publication of this case report.

\section{Competing Interests}

Authors have no potential conflict of interests.

\section{Authors' Contributions}

Design was done by Mushabbab AlAsiri. Data collection was done by Sadeq Al-Dandan, Shomaila Aamir M. Akbar, and Kareema Mohammed Y. Salamah. Manuscript writing was done by Mutahir A. Tunio, Shomaila Aamir M. Akbar, Kareema Mohammed Y. Salamah, and Sadeq Al-Dandan. Manuscript editing was done by Mushabbab AlAsiri, Mutahir A. Tunio, and Kareema Mohammed Y. Salamah.

\section{References}

[1] M. Anand, S. D. Deshmukh, and H. K. Gulati, "Papillary squamotransitional cell carcinoma of the uterine cervix: a histomorphological and immunohistochemical study of nine cases," Indian Journal of Medical and Paediatric Oncology, vol. 34, no. 2, pp. 66-71, 2013.

[2] B. Niederle, S. Rauthe, J. B. Engel, M. Krockenberger, J. Dietl, and A. Honig, "Papillary squamotransitional cell carcinoma of the vagina," The Journal of Obstetrics and Gynaecology Research, vol. 37, no. 12, pp. 1851-1855, 2011.
[3] R. A. Lininger, R. Ashfaq, J. Albores-Saavedra, and F. A. Tavassoli, "Transitional cell carcinoma of the endometrium and endometrial carcinoma with transitional cell differentiation," Cancer, vol. 79, no. 10, pp. 1933-1943, 1997.

[4] P. A. Drew, B. Hong, N. A. Massoll, and D. L. Ripley, "Characterization of papillary squamotransitional cell carcinoma of the cervix," Journal of Lower Genital Tract Disease, vol. 9, no. 3, pp. 149-153, 2005.

[5] C. Koenig, R. P. Turnicky, C. F. Kankam, and F. A. Tavassoli, "Papillary squamotransitional cell carcinoma of the cervix: a report of 32 cases," The American Journal of Surgical Pathology, vol. 21, no. 8, pp. 915-921, 1997.

[6] F. Kokka, M. Verma, N. Singh, A. Faruqi, J. Yoon, and K. Reynolds, "Papillary squamotransitional cell carcinoma of the uterine cervix: report of three cases and review of the literature," Pathology, vol. 38, no. 6, pp. 584-586, 2006.

[7] R. Mirhashemi, P. Ganjei-Azar, M. Nadji, N. Lambrou, F. Atamdede, and H. E. Averette, "Papillary squamous cell carcinoma of the uterine cervix: an immunophenotypic appraisal of 12 cases," Gynecologic Oncology, vol. 90, no. 3, pp. 657-661, 2003.

[8] A. I. Al-Nafussi and R. Al-Yusif, "Papillary squamotransitional cell carcinoma of the uterine cervix: an advanced stage disease despite superficial location: report of two cases and review of the literature," European Journal of Gynaecological Oncology, vol. 19, no. 5, pp. 455-457, 1998.

[9] W.-K. Ng, "Thin-layer (liquid-based) cytologic findings of papillary squamotransitional cell carcinoma of the cervix. Review of cases over a 4-year period with emphasis on potential diagnostic pitfalls," Acta Cytologica, vol. 47, no. 2, pp. 141-148, 2003.

[10] W.-K. Ng, “Thin-layer cytology findings of papillary adenosquamous carcinoma of the cervix: report of a case with histologic correlation and molecular analysis," Acta Cytologica, vol. 47, no. 4, pp. 649-656, 2003.

[11] M. E. Randall, W. A. Andersen, S. E. Mills, and J.-A. C. Kim, "Papillary squamous cell carcinoma of the uterine cervix: a clinicopathologic study of nine cases," International Journal of Gynecological Pathology, vol. 5, no. 1, pp. 1-10, 1986.

[12] Z. Vesoulis and C. A. Erhardt, "Cytologic diagnosis of vaginal papillary squamotransitional cell carcinoma. A case report," Acta Cytologica, vol. 45, no. 3, pp. 465-469, 2001. 


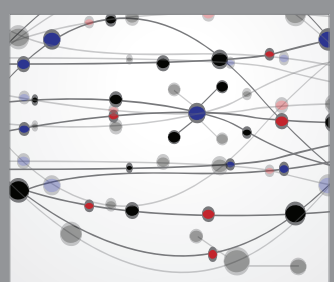

The Scientific World Journal
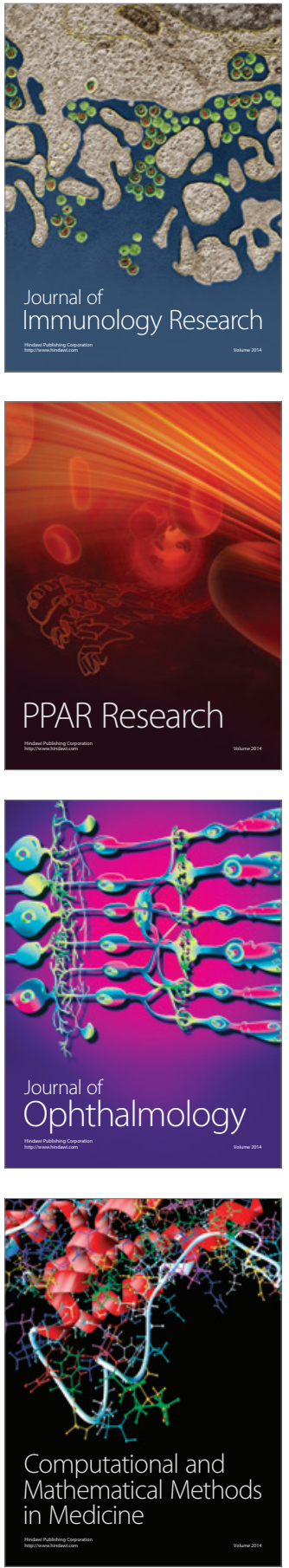

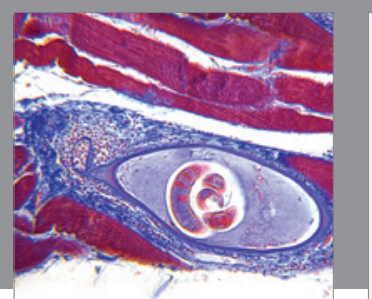

Gastroenterology Research and Practice

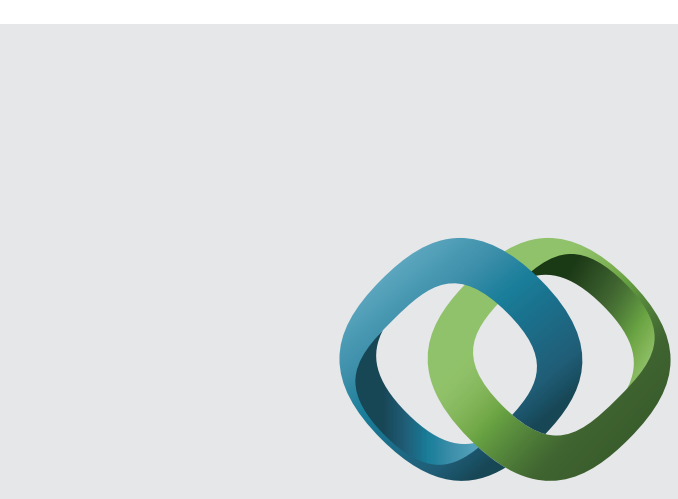

\section{Hindawi}

Submit your manuscripts at

http://www.hindawi.com
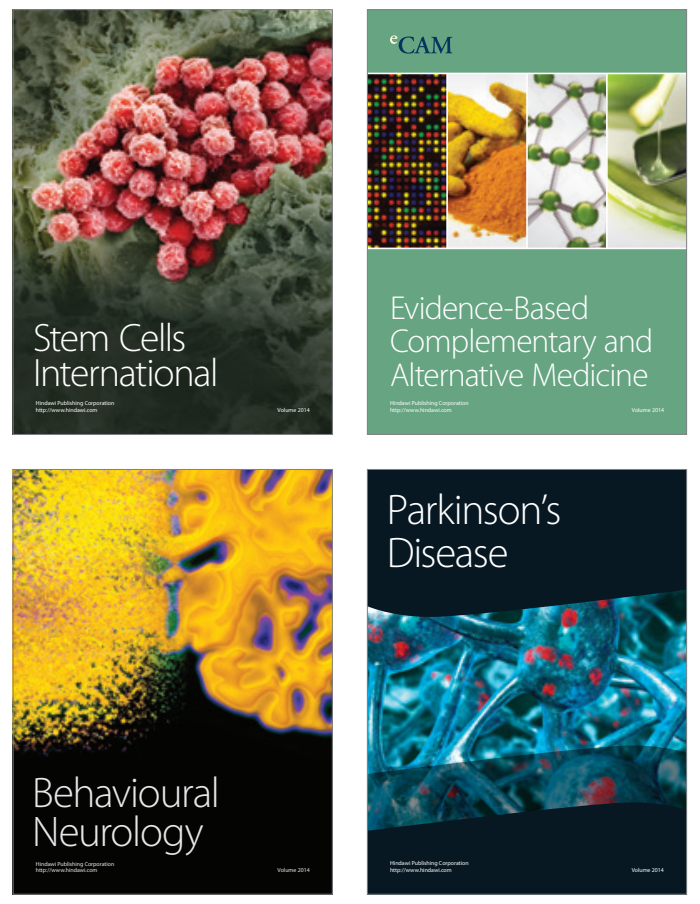
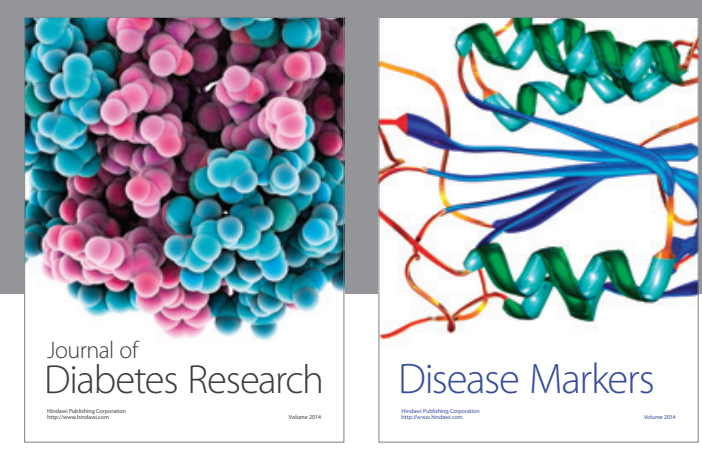

Disease Markers
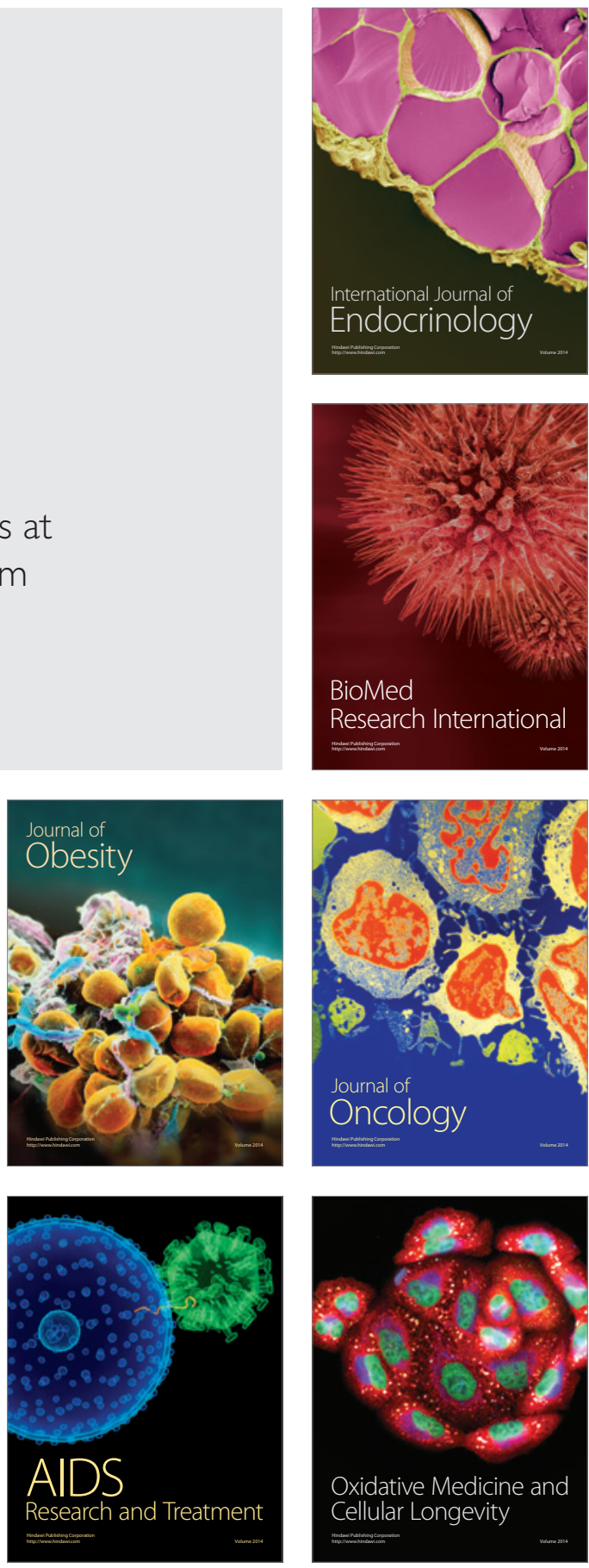